\title{
Identification of Branches in Low-Density Polyethylenes by Fourier Transform Infrared Spectroscopy
}

\author{
Takao USAMI* and Shigeru TAKAYAMA \\ Plastics Laboratory, Mitsubishi Petrochemical Co., Ltd., \\ Tohocho-1, Yokkaichi, Mie 510, Japan
}

(Received January 12, 1984)

\begin{abstract}
Qualitative and quantitative analysis of short chain branches was carried out on a series of low-density polyethylenes by Fourier transform infrared spectroscopy. The peak position of the methyl symmetrical deformation bands around $1378 \mathrm{~cm}^{-1}$ was found to vary with the type of branches and used for identification of the branch type in low-density polyethylenes. The reciprocals of extinction coefficients of the methyl deformation bands were determined for various branch types on the basis of ${ }^{13} \mathrm{C}$ NMR data. The values changed from 0.39 to 0.76 depending on the type of branch. The methyl rocking bands ranging from 880 to $940 \mathrm{~cm}^{-1}$ were examined using brominated samples. The peak positions also depended on the type of branch. For the methylene rocking bands, the peak at $772.2 \mathrm{~cm}^{-1}$ due to the ethyl branch was clearly observed, but that due to the $n$-butyl branch was not detected around $745 \mathrm{~cm}^{-1}$, indicating the $n$-butyl absorption to be located very close to $730 \mathrm{~cm}^{-1}$ rather than $745 \mathrm{~cm}^{-1}$.

KEY WORDS Low-density Polyethylenes / Fourier Transform Infrared Spectroscopy / FTIR / Short Chain Branches / Branch Identification / Methyl Band Positions / Extinction Coefficients /
\end{abstract}

The morphology and physical properties of low-density polyethylenes (LDPEs) largely depend on the content of short chain branches (SCBs). ${ }^{1-4}$ For high pressure low-density polyethylenes (HPLDPEs), many studies have been conducted on SCBs by infrared spectroscopy, ${ }^{4-12}{ }^{1} \mathrm{H}$ or ${ }^{13} \mathrm{C}$ NMR spectroscopy, ${ }^{13-21}$ pyrolysis hydrogenation gas chromatography $^{22-26}$ and $\gamma$-radiolysis ${ }^{27-28}$ and show that there are ethyl, $n$-butyl and $n$-pentyl branches in HPLDPEs.

Recently, linear low-density polyethylenes (LLDPEs) have been manufactured as a third polyethylene using a Ziegler-type catalyst. In these LLDPEs, SCBs are introduced into the backbone chain by copolymerizing ethylene with 1-olefins and the choice of the 1-olefin comonomer makes it possible to introduce a certain select type of SCBs into polyethylenes. This is of much interest, since the properties of LLDPEs change depending on the type of
SCBs. ${ }^{4-5}$ Thus, it is important to identify the types of SCBs.

It is well known that a detailed analysis of branching structure can be made by ${ }^{13} \mathrm{C}$ NMR, but this method is difficult to use routinely. On the other hand, infrared spectroscopy is very popular, but involves such problems as indistinctness and dependence of the extinction coefficient ${ }^{4}$ on the type of branch.

To solve these problems, we analyzed the methyl symmetrical deformation band around $1378 \mathrm{~cm}^{-1}$ by the Fourier transform infrared spectroscopic method (FTIR), which has an excellent reproducibility for peak position and is easily applied for obtaining an accurate difference spectrum. We also examined the methyl rocking bands at $880-940 \mathrm{~cm}^{-1}$ and the methylene rocking bands at 720 $770 \mathrm{~cm}^{-1}$. 


\section{EXPERIMENTAL}

The low-density polyethylenes examined here are listed in Table I. A series of ethylene/ 1-olefin copolymers (LLDPEs) and highdensity polyethylene (HDPE) were prepared using a Ziegler-type catalyst. Four HPLDPEs having 7.9-26.8 branches per 1000 carbon atoms were prepared to examine the samples polymerized under a wide variety of conditions (temperature: $172-330^{\circ} \mathrm{C}$, pressure: $1800-$ $2700 \mathrm{~atm}$, conversion: $4-24 \%$ ).

For FTIR measurements, films about $0.1 \mathrm{~mm}$ thick were prepared by hot pressing at $180^{\circ} \mathrm{C}$. The film thickness was measured by a micrometer and the mean value was obtained from three readings. The densities of the films were measured by the density-gradient column method. Bromination was carried out by exposing $0.5 \mathrm{~mm}$ thick hot pressed sheets to bromine vapor.

For ${ }^{13} \mathrm{C}$ NMR measurements, about 15 $(\mathrm{w} / \mathrm{v}) \%$ solutions in a mixture of $80(\mathrm{v} / \mathrm{v}) \%$ ortho-dichlorobenzene and $20(\mathrm{v} / \mathrm{v}) \%$ perdeuteriobenzene were prepared in a $10 \mathrm{~mm}$ sample tube.

FTIR spectra were recorded on a Digilab FTS-15C FTIR system equipped with a Mercury-Cadmium-Telluride detector. A typical measurement was performed under the following conditions. The number of scans was 400 , the digital spectral resolution, $1 \mathrm{~cm}^{-1}$ and the double precision data processing program was used. After the Fourier transformation of the interferograms, three-point interpolation was applied to obtain difference spectra. In these difference spectra, the reproducibility of the peak position was within $0.1 \mathrm{~cm}^{-1}$.

${ }^{13} \mathrm{C}$ NMR spectra were obtained at $120^{\circ} \mathrm{C}$ by a JEOL-FX200 spectrometer equipped with a JEC-980B minicomputer operating in the quadrature detection at $50.10 \mathrm{MHz}$. The pulse width was $45^{\circ}(9 \mu \mathrm{s})$ and the pulse delay, $2 \mathrm{~s}$. Data processing was carried out using a double precision program. The branch concentration was determined from the integral in-
Table I. Characteristics of the LDPEs studied in this work

\begin{tabular}{lrrrr}
\hline \multicolumn{1}{c}{ LDPEs } & \multicolumn{4}{c}{$\begin{array}{c}\text { Branch concn per 1000 } \\
\text { carbon atoms }\end{array}$} \\
\hline Ethylene/Propene & & 10.0 & 23.5 & \\
Ethylene/1-Butene & 8.0 & 14.0 & 21.0 & 33.5 \\
Ethylene/1-Hexene & & 7.5 & 14.9 & \\
Ethylene/1-Octene & 12.0 & 15.5 & \\
Ethylene/4-Methyl-1-pentene & & 11.0 & 20.0 & \\
HPLDPEs & (D) & (C) & (A) & (B) \\
& 7.9 & 20.4 & 22.0 & 26.8 \\
\hline
\end{tabular}

a The values were determined by ${ }^{13} \mathrm{C}$ NMR for copolymers and by FTIR for HPLDPEs.

tensity ratio for $\beta$ (from the branching point)$\mathrm{CH}_{2}$ carbons to backbone $\mathrm{CH}_{2}$ carbons. The method is described below in detail.

\section{RESULTS AND DISCUSSION}

\section{Identification of Branch Type}

(a) The Methyl Symmetrical Deformation Band around $1378 \mathrm{~cm}^{-1}$. The spectra before and after the subtractive operation for a HPLDPE sample are shown in Figure 1 along with the spectrum of HDPE. It can be seen that a satisfactory difference spectrum obtained using the methylene wagging band around $1369 \mathrm{~cm}^{-1}$ as the subtraction reference. In the same way, difference spectra were obtained for LDPEs having various types of branches. Very few studies have been carried out on the relationship between peak position and branch type. Müller et al. ${ }^{12}$ determined the positions for some types of branches by the peak deconvolution method. Table II shows the peak positions and half widths of the bands for the various types of branches measured by the FTIR difference spectrum method, along with the values reported by Müller et al. The rather wide half width of the methyl branch may be due to its being partly included in the crystalline phase. ${ }^{2,4}$ The reproducibility of the peak position within $0.1 \mathrm{~cm}^{-1}$ makes it possible to identify the type of branch from peak position data. 
(b) The Methyl Rocking Band at 880$940 \mathrm{~cm}^{-1}$. Table II also shows the peak positions of methyl rocking bands determined after overlapping absorptions by double bonds

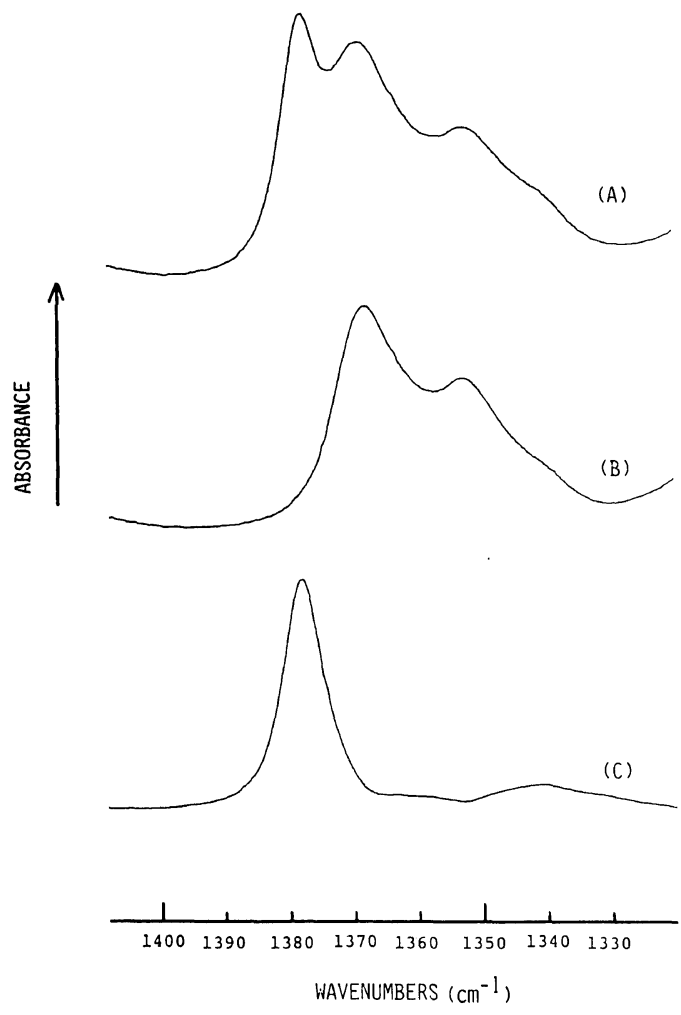

Figure 1. Difference spectra of the methyl symmetrical deformation band for a HPLDPE: (A), HPLDPE; (B), HDPE; (C), (A) - (B) spectrum. were eliminated by bromination. The results imply that the branch type identification can also be made using the methyl rocking band.

(c) The Methylene Rocking Band at 720$770 \mathrm{~cm}^{-1}$. Willbourn ${ }^{6}$ pointed out that the ratio of ethyl to butyl branches can be determined from the methylene rocking bands at $772 \mathrm{~cm}^{-1}$ and $745 \mathrm{~cm}^{-1}$ by the compensation method. Absorption due to the ethyl branches was clearly observed at $772.2 \mathrm{~cm}^{-1}$, but even by the FTIR difference spectrum method, no absorption from the butyl branches was found for an ethylene/1-hexene copolymer. This implies that the methylene rocking absorption band of the butyl branches is situated very close to the large peak at $730 \mathrm{~cm}^{-1}$, due to the methylene in the crystalline phase. Therefore, it is difficult even by the FTIR difference spectrum and compensation methods to observe absorption due to the butyl branch.

(d) Branches in HPLDPEs. In Table II, the methyl symmetrical deformation band of HPLDPEs at $1378.3 \mathrm{~cm}^{-1}$ is situated between the ethyl branch $\left(1379.4 \mathrm{~cm}^{-1}\right)$ and the butyl branch $\left(1378.1 \mathrm{~cm}^{-1}\right)$. In addition, its half width $\left(7.5 \mathrm{~cm}^{-1}\right)$ is wider than those of the ethyl and butyl branches $\left(6.1 \mathrm{~cm}^{-1}\right)$. These findings imply a diversity in the branch types in HPLDPEs. Moreover, the position and broadening of the methyl rocking band at $893.7-892.7 \mathrm{~cm}^{-1}$ indicate the existence of

Table II. Wavenumbers, half-widths and reciprocals of extinction coefficients $K$ of the methyl symmetrical deformation bands and wavenumbers of the methyl rocking bands for various branch types

\begin{tabular}{|c|c|c|c|c|c|c|}
\hline Branch type & Methyl & Ethyl & $n$-Butyl & $n$-Hexyl & Isobutyl & HPLDPE \\
\hline \multicolumn{7}{|l|}{ [Deformation band] } \\
\hline $\begin{array}{l}\text { wavenumber of } \\
\text { the peak }\left(\mathrm{cm}^{-1}\right)\end{array}$ & 1377.3 & 1379.4 & 1378.1 & 1377.9 & $\begin{array}{l}1383.6 \\
1365.6\end{array}$ & 1378.3 \\
\hline Half-width $\left(\mathrm{cm}^{-1}\right)$ & 7.4 & 6.1 & 6.1 & 6.1 & $\begin{array}{l}4.5 \\
5.9\end{array}$ & 7.5 \\
\hline Müller's value ${ }^{12)}$ & 1378.0 & 1379.4 & 1378.3 & 1378.1 & - & 1378.5 \\
\hline $\begin{array}{l}\text { Value of } K \\
\text { [Rocking band] }\end{array}$ & 0.39 & 0.59 & 0.70 & 0.76 & 0.43 & - \\
\hline $\begin{array}{l}\text { wavenumber of } \\
\text { the peak }\left(\mathrm{cm}^{-1}\right)\end{array}$ & 936.7 & $\begin{array}{c}\text { Not } \\
\text { detectable }\end{array}$ & 894.3 & 889.8 & $\begin{array}{l}952.5 \\
919.5\end{array}$ & $\begin{array}{c}\text { Broad peak at } \\
893.7\end{array}$ \\
\hline
\end{tabular}


Table III. Total branch concentrations and distributions $(\%)$ of various branch types in HPLDPEs by ${ }^{13} \mathrm{C}$ NMR

\begin{tabular}{lccccccc}
\hline Samples & $\begin{array}{c}\text { Total } \mathrm{CH}_{3} / \\
1000 \mathrm{C}\end{array}$ & Methyl & Ethyl & Propyl & $n$-Butyl & $n$-Pentyl & $\begin{array}{c}\text { Longer than } \\
n \text {-hexyl }\end{array}$ \\
\hline HPLDPE A & 19.9 & 2 & 32 & 2 & 37 & 13 & 14 \\
HPLDPE B & 24.9 & 2 & 37 & 2 & 34 & 11 & 14 \\
HPLDPE C & 17.3 & 3 & 31 & 2 & 37 & 13 & 14 \\
HPLDPE D & 6.7 & 2 & 34 & 3 & 35 & 11 & 15 \\
\hline
\end{tabular}

butyl, pentyl and longer branches. However, all the samples studied, ranging widely in total branch concentration from 7.9 to 26.8 per 1000 carbon atoms, exhibited peaks at the same position $\left(1378.3 \mathrm{~cm}^{-1}\right)$ and had the same half widths $\left(7.5 \mathrm{~cm}^{-1}\right)$ in the methyl symmetrical band. This indicates that the considerable differences in polymerization conditions giving rise to a wide total branch concentration range has very little effect on the distribution of branch type. This is assured by the ${ }^{13} \mathrm{C}$ NMR results shown in Tabe III. Thus, most commercially available HPLDPEs should have this feature in common.

\section{The Extinction Coefficients of Various} Branch Types

The extinction coefficients of the methyl symmetrical deformation bands for various branch types were determined by applying the FTIR difference spectrum method to the ${ }^{13} \mathrm{C}$ NMR results by the following procedure.

(a) Determination of the Branch Concentrations for Ethylene/1-Olefin Copolymers by ${ }^{13} C N M R$. The ${ }^{13} \mathrm{C}$ NMR measurement conditions used here do not completely satisfy the conditions for quantitative analysis pointed out by Axelson et al. ${ }^{21}$, but the $T_{1}$ values of the $\beta-\mathrm{CH}_{2}$ carbons and the main$\mathrm{CH}_{2}$ carbons are not considered significantly different. For example, the $T_{1\left(\beta-\mathrm{CH}_{2}\right)}$ are $1.4,1.2,1.3 \mathrm{~s}$ and the $T_{\left.1 \text { (main- } \mathrm{CH}_{2}\right)}, 1.6,1.9,2.0 \mathrm{~s}$ for the ethylene/1-butene copolymer, the ethylene/1-hexene copolymer and HPLDPEs, respectively. ${ }^{21}$ The quantitative results for short and long pulse delay times were the
Table IV. Quantitative results by ${ }^{13} \mathrm{C}$ NMR measurements of different pulse delays for an ethylene/1-hexene copolymer

\begin{tabular}{ccc}
\hline Pulse delay & $2 \mathrm{~s}$ & $15 \mathrm{~s}$ \\
\hline Total $\mathrm{CH}_{3} / 1000 \mathrm{C}^{\mathrm{a}}$ (1st run) & 15.1 & 14.9 \\
Total $\mathrm{CH}_{3} / 1000 \mathrm{C}^{\mathrm{a}}$ (2nd run) & 14.9 & 14.8 \\
\hline
\end{tabular}

a The values were calculated from the equation:

$$
N\left(\text { total } \mathrm{CH}_{3} / 1000 \mathrm{C}\right)=\frac{I_{\beta}}{5 I_{\beta}+2 I_{\text {main }}+3 I_{\beta}} \times 1000
$$

where $N$ is the branch concentration, $I_{\text {main }}$ the integral intensity of the main $\mathrm{CH}_{2}$ peak and $I_{\beta}$ is the integral intensity of the $\beta-\mathrm{CH}_{2}$ peak.

same, as shown in Table IV. Full NOEs are also expected for $\mathrm{CH}_{2}$ carbons in the polymer main chain as observed in a HPLDPE ${ }^{21}$ since the $T_{1}$ values are shorter than $2 \mathrm{~s}$. Therefore, it is reasonable to determine the branch concentrations from the integral intensity ratios of $\beta-\mathrm{CH}_{2}$ to main- $\mathrm{CH}_{2}$ in the ${ }^{13} \mathrm{C} \mathrm{NMR}$ spectra for the $2 \mathrm{~s}$ pulse delay. The branch concentration was calculated from

$$
\begin{aligned}
& N(\text { branches } / 1000 \mathrm{C})= \\
& \frac{I_{\beta}}{5 I_{\beta}+2 I_{\text {main }}+n I_{\beta}} \times 1000
\end{aligned}
$$

where $N$ is the branch concentration, $I_{\beta}$, the integral intensity of $\beta-\mathrm{CH}_{2}, I_{\text {main }}$, the integral intensity of the main- $\mathrm{CH}_{2}$ signal, and $n$, the number of branch carbons whose signals do not overlap with that of the main- $\mathrm{CH}_{2}$. An example of calculation is shown below for the butyl branch. 
$\begin{array}{llll}(\beta) & (\alpha) \quad(\alpha) \quad(\beta)\end{array}$

$-\mathrm{CH}_{2}-\mathrm{CH}_{2}-\mathrm{CH}_{2}-\mathrm{CH}-\mathrm{CH}_{2}-\mathrm{CH}_{2}-\mathrm{CH}_{2}-$
$\mid \mathrm{CH}_{2}(3 \mathrm{rd})$
$\mathrm{CH}_{2}$
$\stackrel{\mid}{\mathrm{CH}_{2}}(1 \mathrm{st})$
$\mid \mathrm{CH}_{3}$

There are five main chain carbons whose signals do not overlap with the main- $\mathrm{CH}_{2}$ signal (two $\alpha-\mathrm{CH}_{2}$, two $\beta-\mathrm{CH}_{2}$, and one $\mathrm{CH}$ at the branch point). There are three branch carbons whose signals do not overlap with the main$\mathrm{CH}_{2}$ signal (methyl, first and third $\mathrm{CH}_{2}$ from the branch end). The signal intensity of all the carbons in the PE is thus considered calculable from $I_{\text {main }}+5\left(I_{\beta} / 2\right)+3\left(I_{\beta} / 2\right)$, and the signal from the methyl is expected to have the intensity of $\left(I_{\beta} / 2\right)$. Therefore, the branch concentration $N($ branches $/ 1000 \mathrm{C})$ may be calculated from

$$
\begin{aligned}
N & =\frac{\left(I_{\beta} / 2\right)}{5\left(I_{\beta} / 2\right)+I_{\text {main }}+3\left(I_{\beta} / 2\right)} \times 1000 \\
& =\frac{I_{\beta}}{5 I_{\beta}+2 I_{\text {main }}+3 I_{\beta}} \times 1000
\end{aligned}
$$

(b) Absorbance Values of the Methyl Symmetrical Deformation Band for the Same Samples as in (a). The absorbance values were determined from the FTIR difference spectra of the methyl symmetrical deformation band for the same samples as in (a).

(c) Determination of the Reciprocals of Extinction Coefficients $K$ for Various Branch Types. With the values obtained in (a) and (b), the reciprocals of extinction coefficient $K$ were determined from

$$
N(\text { branch } / 1000 \mathrm{C})=K \times(A / T) / D
$$

where $N$ is the branch concentration determined by ${ }^{13} \mathrm{C}$ NMR, $A$, the absorbance value estimated by FTIR, $T$, the film thickness in $\mathrm{cm}$, and $D$, the film density in $\mathrm{g} \mathrm{cm}^{-3}$. The values of $K$ for various branch types are shown in Table II.

(d) Determination of the Total Branch Concentration and the Branch Type Distribution for HPLDPEs. The ${ }^{13} \mathrm{C}$ NMR spectrum of HPLDPE contains the following signals unique to the type of branch:

methyl branch, the methyl carbon resonance around $20 \mathrm{ppm}$.

ethyl branch, the methyl carbon resonances around 11 and $8 \mathrm{ppm}$.

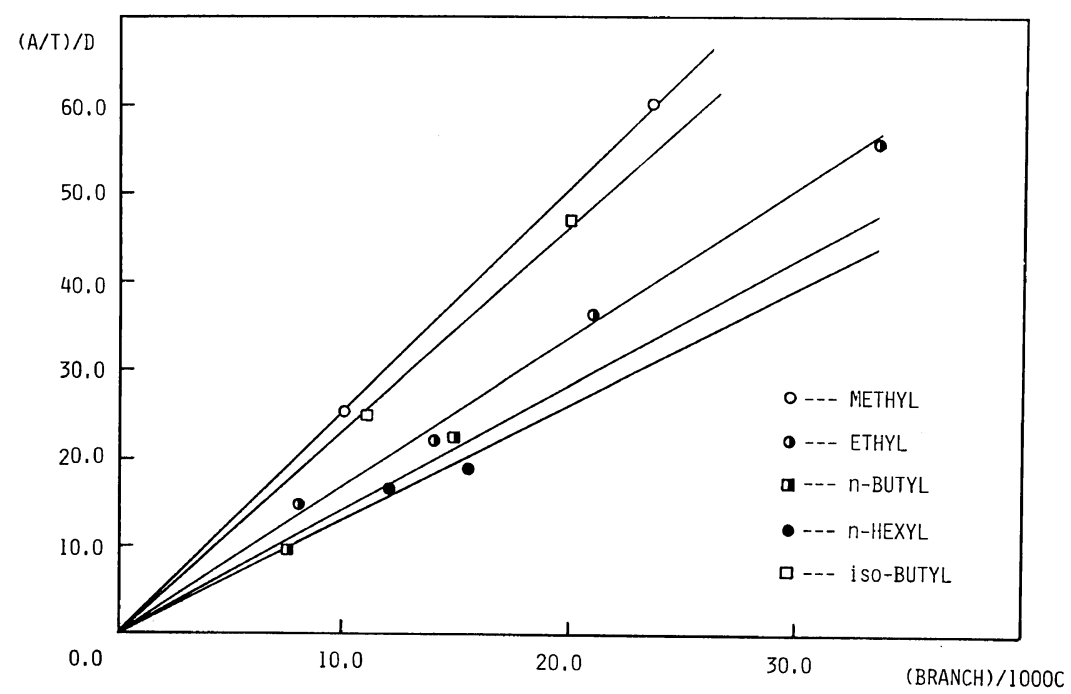

Figure 2. Plots of FTIR (A/T)/D vs. ${ }^{13} \mathrm{C}$ NMR branch concentration to determine the reciprocal of absorption coefficient $K$. 
propyl branch, the methyl carbon resonance around $14.6 \mathrm{ppm}$.

$n$-butyl branch, the resonance of the first $\mathrm{CH}_{2}$ from the branch end around $23 \mathrm{ppm}$.

$n$-pentyl and longer branch, the resonances of the second $\mathrm{CH}_{2}$ from the branch end around 33 and $32 \mathrm{ppm}$, respectively.

More accurate chemical shifts and structures assigned to these signals can be found elsewhere. $^{30}$ The concentrations and distribution of various branch types can be determined from the integral intensities of these signals. However, these integral intensities are not considered to give the correct concentrations in the ${ }^{13} \mathrm{C}$ NMR measurements for the $2 \mathrm{~s}$ pulse delay and hence should be corrected using the intensity data for the carbons in ethylene/1-olefin copolymers. The calibration factors for various carbons relative to the $\beta$ $-\mathrm{CH}_{2}$ in the ethylene/1-olefin copolymers were determined for the $2 \mathrm{~s}$ pulse delay. The results are shown in Table V. With them, the branch concentrations and distribution were calculated using the following equation:

$N($ total branches $/ 1000 \mathrm{C})=\frac{1000 \times\left(I_{\mathrm{Me}} / 0.90+I_{\mathrm{Et}} / 0.84+I_{\mathrm{Pr}} / 0.83+I_{\mathrm{Bu}} / 0.90+I_{\mathrm{Pe}} / 0.90+I_{\mathrm{Lg}} / 0.80\right)}{I_{\text {main }}+5.5\left(I_{\mathrm{Et}} / 0.84\right)+\left(I_{\mathrm{Pr}} / 0.83\right)+8.0\left(I_{\mathrm{Bu}} / 0.90+I_{\mathrm{Pe}} / 0.90+I_{\mathrm{Lg}} / 0.80\right)}$

where $I_{\mathrm{Me}}$ is the integral intensity of the methyl resonance in the methyl branch, $I_{\mathrm{Et}}$, that in the ethyl branch, $I_{\mathrm{Pr}}$, that in the propyl branch, $I_{\mathrm{Bu}}$, the integral intensity of the resonance of the first $\mathrm{CH}_{2}$ from the branch end in the $n$ butyl branch, $I_{\mathrm{Pe}}$, that of the second $\mathrm{CH}_{2}$ in the $n$-pentyl branch, and $I_{\mathrm{Lg}}$, that of the second $\mathrm{CH}_{2}$ in the longer branch. This equation is applicable to HPLDPEs, because the methyl, ethyl and propyl branches in HPLDPEs are considered to be in the paired forms of 1,4methyl ethyl, 1,3-ethyl ethyl and 1,3-ethyl propyl. $^{30}$ Therefore, the signal intensity of all the carbons whose signals do not overlap with the main- $\mathrm{CH}_{2}$ signal can be calculated from

$$
\begin{gathered}
5.5\left(I_{\mathrm{Me}} / 0.90\right)+5.5\left(I_{\mathrm{Et}} / 0.84\right)+6.5\left(I_{\mathrm{Pr}} / 0.83\right) \\
\quad-5.5\left(I_{\mathrm{Me}} / 0.90\right)-5.5\left(I_{\mathrm{Pr}} / 0.83\right) \\
\quad+8.0\left(I_{\mathrm{Bu}} / 0.90+I_{\mathrm{Pe}} / 0.90+I_{\mathrm{Lg}} / 0.80\right) .
\end{gathered}
$$

The minus terms are added because of the duplication in counting. As a result, the denominator in the above equation for $N$ becomes

$$
\begin{aligned}
& 5.5\left(I_{\mathrm{Et}} / 0.84\right)+\left(I_{\mathrm{Pr}} / 0.83\right) \\
& +8.0\left(I_{\mathrm{Bu}} / 0.90+I_{\mathrm{Pe}} / 0.90+I_{\mathrm{Lg}} / 0.80\right)+I_{\text {main }} .
\end{aligned}
$$

Methyl : Ethyl : Propyl : $n$-Butyl : $n$-Pentyl :

Longer $($ distribution $)=\left(I_{\mathrm{Me}} / 0.90\right):\left(I_{\mathrm{Et}} / 0.84\right)$ :
Table V. Integral intensity ratios of carbons in the branches to $\beta-\mathrm{CH}_{2}$ for a series of ethylene/1-olefin copolymers determined from $2 \mathrm{~s}$ pulse delay ${ }^{13} \mathrm{C}$ NMR measurements

\begin{tabular}{lccc}
\hline & \multicolumn{3}{l}{$\begin{array}{l}\text { Integral intensity ratio to } \beta-\mathrm{CH}_{2}{ }^{\mathrm{a}} \\
\text { (numbering from the branch end) }\end{array}$} \\
\cline { 2 - 4 } & $3-\mathrm{CH}_{2}$ & $2-\mathrm{CH}_{2}$ & $1-\mathrm{CH}_{3}$ \\
\hline Methyl & - & - & 0.90 \\
Ethyl & - & - & 0.84 \\
Propyl & - & - & $0.83^{\mathrm{b}}$ \\
$n$-Butyl & - & 0.90 & 0.81 \\
$n$-Pentyl & $0.90^{\mathrm{b}}$ & - & - \\
Longer than & 0.80 & - & - \\
$n$-hexyl & & & \\
\hline
\end{tabular}

a The integral intensity of $\beta-\mathrm{CH}_{2}$ is devided by two in the calculation of the ratios.

b These were deduced from the values of other branches, but are considered reasonable and not to give rise to significant error.

$$
\left(I_{\mathrm{Pr}} / 0.83\right):\left(I_{\mathrm{Bu}} / 0.90\right):\left(I_{\mathrm{Pe}} / 0.90\right):\left(I_{\mathrm{Lg}} / 0.80\right)
$$

The results obtained are shown in Table III.

(e) The Extinction Coefficients of HPLDPEs. With the $K$ values in Table II and the branch distribution in Table III, the reciprocals of extinction coefficients of HPLDPEs were determined, and the values shown in Table VI were obtained. In the 
calculation, it was assumed that the $K$ values of the propyl, $n$-pentyl and longer branches are 0.65 (the average of ethyl and $n$-butyl), 0.73 (the average of $n$-butyl and $n$-hexyl) and 0.76 (the same as hexyl), respectively. However, these values seem to be almost the same as the correct values and not to cause much error. The total branch concentrations determined with these $K$ values are shown in Table VI. The reciprocals of extinction coefficients of the four HPLDPEs are almost the same, giving an average value of 0.67 which may be considered common to most commercially available HPLDPEs.

A comparison of the total branch concentrations of four HPLDPEs presented in Table III and Table VI shows that the ${ }^{13} \mathrm{C}$ NMR values are smaller than those of FTIR.

Table VI. Reciprocals of extinction coefficients and branch concentrations determined by the FTIR method for HPLDPEs

\begin{tabular}{lrrrr}
\multicolumn{1}{c}{ HPLDPE } & A & B & C & D \\
\hline Value of $K$ & 0.67 & 0.66 & 0.67 & 0.67 \\
Branch conc./1000 C & 22.0 & 26.8 & 20.4 & 7.9 \\
\hline
\end{tabular}

This may be due to unassignable broad signals located around 13 and $8.7 \mathrm{ppm}$. These signals were neglected in the determination of the ${ }^{13} \mathrm{C}$ NMR values, since they could not be clearly observed. However, they gave some integral intensities in the ${ }^{13} \mathrm{C}$ NMR spectrum shown in Figure 3. In Figure 3, the resonances located in the range from 13 to $7 \mathrm{ppm}$ can be assigned to the ethyl branches for the following reasons.

(a) The resonance of the 1,2-paired (head to head) ethyl branches appears at 12.86 ppm. ${ }^{32}$ Therefore, the broad peak around 12.9 ppm can be assigned to the 1,2-paired ethyl branches having some differences with the neighboring structures.

(b) The resonance around $11 \mathrm{ppm}$ assigned to the ethyl branch is considered to be in the 1,3-paired form and splits into three peaks because of differences in steric and neighboring structures. ${ }^{30}$

(c) The resonance around $8 \mathrm{ppm}$ assigned to the ethyl branch attached to the quaternary carbon $^{19}$ is also considered to be in the 1,3paired form and splits into two peaks because of differences in the steric and neighboring structures. ${ }^{30}$ The broad peak around $8.7 \mathrm{ppm}$

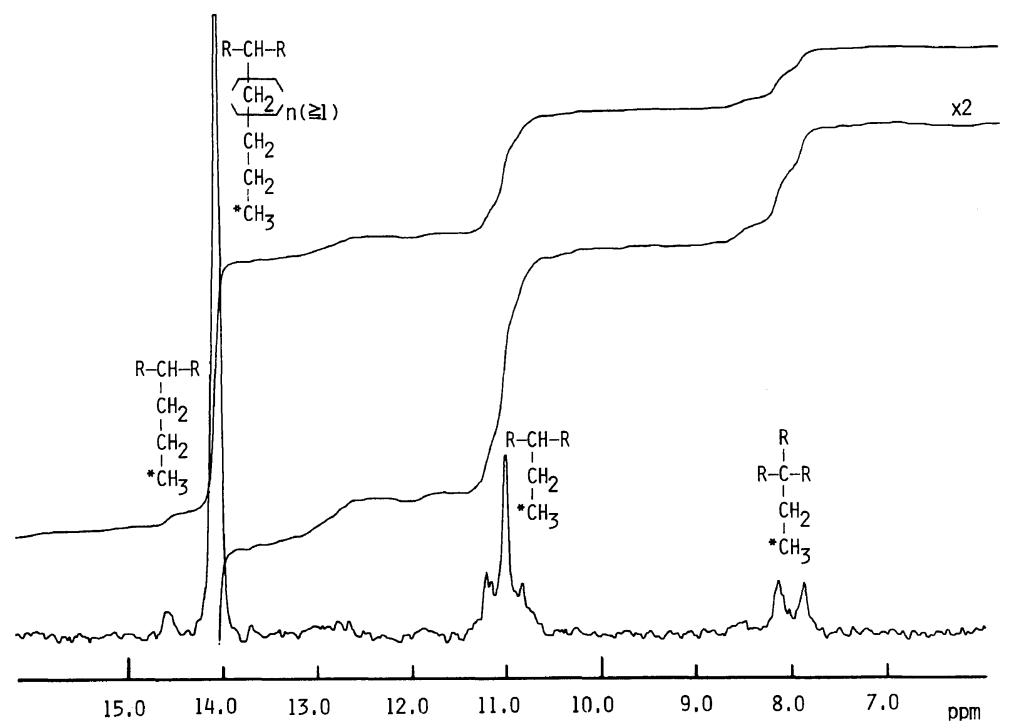

Figure 3. ${ }^{13} \mathrm{C}$ NMR spectrum of the methyl resonances from 7 to $15 \mathrm{ppm}$, showing integral curves and assignments. 
Table VII. Modified ${ }^{13} \mathrm{C}$ NMR quantitative results for HPLDPEs and FTIR results determined with modified $K$ values obtained from the ${ }^{13} \mathrm{C}$ NMR results

\begin{tabular}{ccccc}
\hline HPLDPE & A & B & C & D \\
\hline $\begin{array}{c}\text { Modified }{ }^{13} \mathrm{C} \text { NMR } \\
\text { quantitative results }\end{array}$ & 21.6 & 26.9 & 18.6 & 7.3 \\
$\begin{array}{c}\text { Modified } K \text { value } \\
\begin{array}{c}\text { FTIR results } \\
\text { from the } K \text { value }\end{array}\end{array}$ & 0.66 & 0.66 & 0.66 & 0.66 \\
\hline
\end{tabular}

may be assigned to the ethyl branches attached to the quaternary carbon and having some differences with neighboring structures.

Thus, by counting the integral intensities due to the ethyl branches, the agreement between ${ }^{13} \mathrm{C}$ NMR and FTIR total branch concentration is satisfactory (see Table VII). The $K$ values corresponding to the modified branch type distributions are also shown in Table VII. Since the $K$ values in Table VII are nearly equal to those in Table VI, the FTIR method should be reliable for determining the total branch concentrations of LLDPEs as well as HPLDPEs.

Acknowledgement. The authors express their sincere appreciation to Prof. Shin Tsuge for his very helpful comments.

\section{REFERENCES}

1. M. J. Roedel, J. Am. Chem. Soc., 75, 6110 (1953).

2. M. J. Richardson, P. J. Flory, and J. B. Jackson, Polymer, 4, 221 (1963).

3. F. J. Balta-Calleja and D. R. Rueda, Polym. J., 6, 216 (1974).

4. K. Shirayama, S. Kita, and H. Watabe, Makromol. Chem., 151, 97 (1972).

5. F. P. Reding and C. M. Lovell, J. Polym. Sci., 21, 157 (1956).

6. A. H. Willbourn, J. Polym. Sci., 34, 569 (1959).

7. K. Teranishi and K. Sugawara, Kobunshi Kagaku, 23, 512 (1966).
8. S. Badilescu, M. Toader, H. Oprea, and I. Badilescu, Mater. Plast., 7, 468 (1970).

9. C. Baker and W. F. Maddams, Makromol. Chem., 177, 437 (1976).

10. M. A. McRae and W. F. Maddams, Makromol. Chem., 177, 449 (1976).

11. D. R. Rueda, F. J. Balta-Calleja, and A. Hidalgo, Spectrochim. Acta, 35A, 847 (1979).

12. G. Müller, E. Schröder, and J. Osterode, Acta Polym., 32, 270 (1981).

13. D. E. Dorman, E. P. Otocka, and F. A. Bovey, Macromolecules, 5, 574 (1972).

14. J. C. Randall, J. Polym. Sci., Polym. Phys. Ed., 11, 275 (1973).

15. T. Hama, T. Suzuki, and K. Kosaka, Kobunshi Ronbunshu, 32, 91 (1975).

16. M. E. A. Cudby and A. Bunn, Polymer, 17, 345 (1976).

17. F. A. Bovey, F. C. Schilling, F. L. McCrackin, and H. L. Wagner, Macromolecules, 9, 76 (1976).

18. H. N. Cheng, F. C. Schilling, and F. A. Bovey, Macromolecules, 9, 363 (1976).

19. D. E. Axelson, G. C. Levy, and L. Mandelkern, Macromolecules, 12, 41 (1979).

20. A. Nishioka, Y. Mukai, M. Ohuchi, and T. Imanari, Bunseki Kagaku, 29, 774 (1980).

21. D. E. Axelson, L. Mandelkern, and G. C. Levy, Macromolecules, 10, 557 (1977).

22. M. Seeger and E. M. Barrell, II, J. Polym. Sci., Polym. Chem. Ed., 13, 1515 (1975).

23. M. Seeger, E. M. Barrell, II, and M. Shen, J. Polym. Sci., Polym. Chem. Ed., 13, 1541 (1975).

24. M. Seeger and R. J. Gritter, J. Polym. Sci., Polym. Chem. Ed., 15, 1393 (1977).

25. Y. Sugimura and S. Tsuge, Macromolecules, 12, 512 (1979).

26. Y. Sugimura, T. Usami, T. Nagaya, and S. Tsuge, Macromolecules, 14, 1787 (1981).

27. P. M. Kamath and A. Barlow, J. Polym. Sci., A, 5, 2023 (1967).

28. T. N. Bowmer and J. H. O'Donnell, Polymer, 18, 1032 (1977).

29. "Absorbance of Polyethylene due to Methyl Groups at $1378 \mathrm{~cm}^{-1}$," The American Society of Testing and Materials, Spec. Tech. Publ., D 2238-64, 1964.

30. T. Usami and S. Takayama, Macromolecules, in press.

31. J. J. Dechter and L. Mandelkern, J. Polym. Sci., Polym. Phys. Ed., 18, 1955 (1980).

32. Marie-Florence Grenier-Loustalot, J. Polym. Sci., Polym. Chem. Ed., 21, 2683 (1983). 